\section{ESSENTIALS OF SURGERY FOR DENTAL STUDENTS}

By J. Cosbie Ross, M.B., Ch.M., F.R.C.S. Second edition. Pp. vii +296 , with 207 illustrations, some in colour. Edinburgh: E. \& S. Livingstone Ltd. 1952. 27s. 6d.

This book presents the esséntial surgical subjects with which a dental surgeon should be familiar in a fashion which students should find very readable and easy to assimilate. In general the author has dealt effectively with the problem of what to include in a book of this size, and few practising dental surgeons will find much to disagree with in the chapters dealing with subjects within their usual experience. The general surgical facts presented are well balanced and up to date, but many surgeons would not recognize prophylactic block dissection of the neck as a clinical treatment in malignant growth of the mouth. They would wait until glands are palpable.

On the whole this book is very well illustrated, but it is unfortunate that Fig. I is ambiguous. The impression given to many readers is that the demonstrator is doing the opposite to what is intended.

This book can certainly be recommended to dental students, who will find it dovetails well with textbooks of dental surgery dealing in more detail with subjects in their special sphere.

\section{RADIATIONS AND LIVING CELLS}

By F. G. Spear, M.D., M.A., D.M.R.E. Pp. xii +222 , with 60 illustrations. London: Chapman $\&$ Hall Ltd. 1953. I8s.

In his preface, the author hopes that his book will serve ' as a contribution to bridging the gap between medical physics and radiation biology,' and there can be no doubt that he has succeeded.

In ten chapters the author roves over the whole field of radiation biology in a manner both lucid and erudite. After a short historical introduction, the structure of the cell is described and an excellent account of normal cell division is given. The scope of radiation biology is then briefly outlined, and this leads logically to the type of biological response that may be observed after different doses of penetrating irradiation of a variety of experimental material.

There follows a more detailed account of the action of high voltage $\mathrm{X}$-rays and gamma rays on the tissues of the body. The skin and alimentary canal, the circulatory and generative systems are selected for more detailed study, and consideration of each is preceded by an account of the normal histological appearances. For this, Dr. Spear will deserve the gratitude of the many doctors who start a course in radiology with their memories of the normal somewhat dim from disuse!

Irradiation of the whole body, such as might occur after the explosion of an atomic bomb, is dealt with at some length, and this is followed by a general account of the treatment of malignant disease by radiotherapy. The book concludes by discussing some of the theories of the mode of action of penetrating rays on living cells:

Radiobiology covers a number of disciplines and techniques, most of which are applied to obscure, though fundamental problems; some applications of these studies to clinical practice will emerge in time. A body of cytological and histological fact already exists and it is well set out in this book. Without this knowledge the intelligent practice of radiotherapy is impossible. Radiologists are already indebted to Dr. Spear for his work in this field.

The knowledge contained in this book should be part of every radiotherapist's grounding. Its clarity and simplicity should make it very attractive to many others, including hospital physicists.

The book is well produced and abundantly illustrated. Two minor criticisms may be mentioned; it would be helpful if, as far as possible, illustrations could face the page referring to them in the text, and the magnification of the many photomicrographs indicated. No doubt these points will be put right in the subsequent editions that are bound to be called for.

\section{RECENT ADVANCES IN MEDICINE}

By G. E. Beaumont, M.A., D.M., F.R.C.P., D.P.H., and E. C. DoDDS, M.V.O., D.Sc., PH.D., M.D., F.R.C.P., F.R.I.C., F.R.S.ED., F.R.S. Thirteenth edition. Pp. 397 with 59 illustrations. London: J. \& A. Churchill. 1952. 27s. 6d.

The new chapters and alterations in the $13^{\text {th }}$ edition of this popular book are valuable resumés of some of the recent changes in medicine.

A short chapter on the collagen diseases gives a simple review of the opinions of the three main groups of workers responsible for the conception of the possible interrelationship of such conditions as rheumatoid arthritis, lupus erythematosus and periarteritis nodosa as well as several other obscure disease entities. Treatment with ACTH or cortisone is discussed stressing some of the contraindications, and accepting no more than that either may cause a temporary remission in any of the collagen diseases. Curiously, no mention is made of the great benefit obtained from local cortisone in iridocyclitis, which, in many instances, is part of collagen disease.

The section on antibiotics has been brought up to date to include all those of well-established value and fairly readily available. It would seem a pity unnecessarily to spread over three pages the table of the comparative therapeutic values of penicillin, streptomycin, aureomycin, chloramphenicol and the sulphonamides. The antihistamine drugs are reviewed and a theoretical consideration for their use in various allergic manifestations is discussed. $A$ very lucid account of the use of radioactive and stable isotopes is given. The use of radioactive iodine, both in diagnosis and treatment of thyroid disorders, offers the main clinical advance. No 